\title{
Reputation Management in the Japanese Insurance Marketplace
}

\author{
Kunio Ishihara \\ Tokio Marine \& Nichido Fire Insurance Co. Ltd., 2-1, Marunouchi, 1-Chome, Chiyoda-ku, \\ Tokyo 100-8050, Japan. \\ E-mail: masaaki.nagamura@tmnf.jp
}

As seen in many other parts of the globe, there is a growing public awareness of corporate ethics in Japan. The deregulation process in the Japanese insurance marketplace is causing a shift toward a market in which a customer's choice becomes the defining factor in a carrier selection. The reputation of the carrier plays a critical role in this selection. The author believes that the origin of reputation management evolves from a business conduct stemming from gaining each customer's trust. One of the initiatives that is currently in force on a company-specific basis is to "expand the scope and activities of insurance," to enrich the function of insurance products beyond its traditional concept. The hope is that this initiative will contribute to society's growth, which will ultimately enhance the company's positive reputation. Meanwhile, there is an ongoing effort to design a quantitative analysis methodology to enable a truly functional model of reputation management.

The Geneva Papers (2006) 31, 446-453. doi:10.1057/palgrave.gpp.2510089

Keywords: corporate social responsibility; reputation management; environmental preservation; human power

\section{Introduction - changes in the environment surrounding corporate reputation}

\section{Strategic importance of intangible asset management}

Amidst numerous managerial challenges that capture a corporate manager's attention, improving corporate value commands the top priority over others, setting back even the traditional challenge of penetrating the market. It has now become a common observation that intangible assets, which include intellectual property and corporate reputation, rather than tangible assets, create most of corporate value. As the universal shift from an industrialized society to an intellectual society takes place, the opportunity to create corporate value depends heavily on managing or maintaining a trustworthy brand image, quality of operation, skilled and motivated workforce, and corporate reputation. Corporate managers are thus devoting themselves to establishing their unique strategic management protocol and implementing it in their organization.

\section{Growing public awareness of corporate ethics}

Japan is not an exception to increased public concern over corporate social responsibilities (CSRs), which embrace philosophies such as regulatory compliance, 
corporate governance, ${ }^{1}$ and socially responsible investment. A corporate manager may not survive without performing in harmony with the company's social responsibility and without striving hard to improve the corporate reputation. Any company that fails to comply with social orders will be immediately forced out of the market, resulting in bankruptcy or declining performance. Japanese corporate managers are thus constantly reminded of the importance of corporate governance issues.

\section{Evolving information technology as a driving force}

Information technology (IT) is another critical factor that helps promote the importance of managing corporate reputation. With today's IT environment, any unexpected incident could enhance or destroy corporate reputation in an instant. Advancement in information networks like the internet merely accelerates the formation of reputation. Those who lag behind this acceleration are inevitably exposed to hazards affecting reputational risk, which could be fatal to a company. A corporate manager should not only be concerned with the appropriateness of matters in managing corporate reputation, but also with the swiftness in addressing such matters.

\section{Insurance market deregulation}

The changing environment that surrounds corporate reputation applies to companies of any industry. However, the Japanese insurance market has experienced a deregulation process, which helped the industry recognize the issue even more acutely. The deregulation, coupled with de-tariffication, generated a clear shift toward a market in which a consumer chooses his/her service provider rather than the opposite. ${ }^{2}$ The customary change triggered by the deregulation caused a heightened significance of "reputation" as an element of consumer's choice.

In the Japanese insurance marketplace, "pre-deregulation" and "post-deregulation" are frequently used comparative concepts to describe the change in customs and practices observed through the transition. One may find the growing awareness and discussions involving reputation issues as one of the notable aspects in the "postderegulation" era, especially from the marketing strategy point of view.

\section{Origin of reputation management}

Viewing our company-specific business activities and their relationship with reputation, there is no doubt that reputation is playing an increasingly prominent role in various levels of our operations; and this may be applicable to other market

${ }^{1}$ In Japan, the so-called "collapse of the bubble economy" in the 1990s, followed by corporate scandals, drew public attention to corporate governance. This prompted revisions of the legal framework in the areas of Commercial Code as well as Securities and Exchange Law.

2 The revised Insurance Business Law was enacted on 1 April 1996. With the revised act, new concepts, including de-tariffication, insurance broker system, and mutual entrance between life and non-life insurance business through subsidiaries, were introduced. 
participants as well. From a marketing perspective, reputation is a major determining factor for a consumer in evaluating a carrier's credibility. Reputation is a critical issue from a human resource or recruiting standpoint as well, since it plays a key role in attracting a quality workforce. ${ }^{3}$ Lastly, from an investor relations' point of view, a company's senior management's reputation for reliability and capability, and the company's potential for further growth can never be neglected.

Under the circumstance that has been discussed, our company-specific philosophy of reputation management would be the company philosophy, which states "business conduct stemming from gaining trust from customers". Who will then be responsible for practicing this concept? Obviously, corporate executives are expected to communicate with various stakeholders, sense the evolution vividly, and take a swift action to manage the corporate reputation. The question arises, however, whether you can rely solely on corporate executives' performance to manage reputation. Although it may be regarded as one of the requirements, it is not necessarily sufficient. There is no doubt that strong leadership sets a platform in managing corporate reputation. However, it is crucial that each individual associate on the frontline who interacts with each stakeholder absorb and digest the aforementioned corporate philosophy and practice it as his/her own belief as part of the daily operation.

Insurance products, like other types of financial products, are invisible in nature. Therefore, the associate who embodies the product, equipped with the so-called "human power", 4 should thoroughly show the product value to customers and each stakeholder. By incorporating this, the company's reputation will improve. The importance of nurturing "human power" is so essential to the insurance industry that one may sense the need of exploiting reputation management with an emphasis on encouraging each individual's internal reform, instead of exhausting resources by seeking instantly appealing activities. In addressing "human power" to the associates, the following three components are referred to: first, ability to think and act from the other's perspective; second, potential strength to act as a professional; and third, vitality produced as a result of combining components one and two.

\section{Viewpoints in exercising reputation management}

For a Japanese company, there are two main pillars with company-specific reputation management, namely "Japanese domestic" and "overseas".

To cope with the first pillar (a focus on the Japanese domestic market), one needs to bear in mind the traditional sales practice that involves customer interface conducted by insurance agents who are positioned as business partners. It is therefore indispensable to share the corporate value with the agents and work together with them towards formulating a solid reputation.

\footnotetext{
${ }^{3}$ Under the traditional Japanese corporate recruiting system, college students go through a series of interviews with companies of their choice. A number of research institutes publish popularity rankings of companies based on student polls, which not only helps students, but also corporate managers, to gauge their corporate reputation.

${ }^{4}$ Addressed at the Fourth Nikkei CSR Symposium.
} 
Corporate reputation is something that formulates gradually through each stakeholder's experience interacting with the company. Each associate has his/her field of operation through which communication with outside stakeholders takes place. However, it is evident that agents have the most frequent interaction with stakeholders. With over 69,000 agents supporting the Japanese operation, there is no doubt that the most influential reputation is created first through their interaction with the customer. Nourishing a trustful partnership with agents has been our first priority in conducting business, but it is now reaffirmed that this viewpoint is also important in the context of reputation management.

The second pillar focuses on the overseas operation. Both Millea Holdings, Inc. ${ }^{5}$ and Tokio Marine \& Nichido are actively exploring business opportunities outside of Japan. A number of points need to be considered when a Japanese company ventures into a foreign market, from a reputation management point of view. The proverb "When in Rome, do as the Romans do" appropriately sheds light on some aspects of corporate reputation management. In this context, one may raise the question of "what value can we provide to the local stakeholders?" When assessing the business opportunity in the local overseas market, there is a belief that strategic decisions based on Japanese values, rather than the local values, will only lead to a failure. It does not matter what reputation a company has established in its home country when ensuring valuable service to the local market. Unless the company succeeds in offering value acceptable to the local market, no positive influence on corporate reputation can be expected. The company must be acknowledged by consumers of the targeted local market as one of the local players to exercise reputation management in foreign markets.

Regardless of the country, the potential of local associates should be valued as the origin of reputation management. No matter where the operation is based, local associates are the most important source of delivering the distinctive message of "who we are". By maintaining an adequate level of communication with the local associates, verbal communication naturally spreads throughout the local community. The positive effect of creating a good local reputation can never be underestimated. Efforts have been made to communicate with the local associates to the fullest extent, from the belief that "the local associates will share corporate manager's ideas of providing value to customers", in other words, "being of one team and one mind".

\section{Reputation management activities currently in force}

\section{Practicing CSR through the core business}

The value of introducing CSR has become a popular subject among Japanese enterprises. Many have implemented CSR standards based on their own interpretation, and have exercised it actively. It is now a common recognition that CSR activities have considerable influence over a company's reputation.

\footnotetext{
${ }^{5}$ Established in April 2002, as a holding company of Tokio Marine \& Fire Insurance Company and Nichido Fire Insurance Company. The two operating companies merged in October 2004.
} 
"Practicing CSR through the core insurance business" is a basic principle that is frequently reinforced internally. Non-life insurance is a "mutual aid" system that inherits a strong social and public character. Thus, excelling in the core business and contributing to the continuous social development by utilizing its function is the social mission of non-life insurance companies. If each associate digests and puts this CSR essence into practice, then the company's reputation should improve naturally. Practicing CSR can be seen as the core of the reputation management.

\section{Expansion of scope and activities of insurance}

Based on the CSR concept as stated above, a slogan called "expand scope and activities of insurance" was set up to enrich the function of insurance products. ${ }^{6}$ This surpasses the traditional insurance concept of "paying out claims in the event of a loss". The concept intends to provide the sense of trust and safety to the insured even before or after the loss occurrence. This is accomplished by offering statistics and skills that have been stored and accumulated in the company database to assist them in loss prevention and post-loss recovery. While this ambitious initiative may even open up a new business domain, it is hoped to contribute to society's sustainable growth, which will ultimately enhance the company's positive reputation.

\section{Coping with environmental issues}

In general, Japanese corporations are eagerly involved in environmental issues through various CSR activities. In a sense, these activities illustrate how environmental issues are taken seriously by Japanese corporations. However, one may find some unique methodologies adopted. On a company-specific basis, we are implementing environmental preservation through (1) conducting business activities in the fields of insurance products, ${ }^{7}$ claims, ${ }^{8}$ and financial services, ${ }^{9}$ (2) minimizing environmental burden through business conduct, and (3) promoting environmental education ${ }^{10}$ in and out of the company. The so-called "Mangrove Reforestation Project", ${ }^{11}$ also dubbed as "insurance for the planet", is a symbolic activity in an attempt to protect the global environment.

\footnotetext{
${ }^{6}$ A newly introduced automobile insurance policy (1) provides assistance to an insured even in the case where the insured was not at fault, and (2) allows the insured to choose the type of coverage after a first party bodily injury loss. In addition, there is a medical insurance policy designed for diabetes made available for patients already diagnosed as diabetic.

${ }^{7}$ Insurance products aiming at helping to stabilize the wind power generation business; applying discounts on automobile insurance coverage to low pollution, low fuel consumption vehicles.

${ }^{8}$ Participating in campaign run by the General Insurance Association of Japan to promote extended use of recycled exchange parts and the use of repaired parts in handling automobile claims.

${ }^{9}$ Investing in environmental venture businesses in the fields such as recycling, energy conservation, and biomass related.

${ }^{10}$ Environmental awareness raising activities include "Green Lessons - the Mangrove Story" in which company associates demonstrate their experience from participating in the "Mangrove Reforestation Project'.

11 "Mangrove Reforestation Project": 3,000 hectares of mangrove forests are estimated to be a scale
} 
As was discussed earlier, regardless of the type of industry, whenever a company ventures into a foreign market, it must consider what value the company can offer to the local market based on local standards. Many Japanese companies have focused on environmental issues, and with the unique experience that we have encountered, Japanese companies are expected to take the leadership and play a vital role in promoting such activities on a global scale. If Japanese companies can prove that they can provide value on environmental issues, which are truly global in nature, their foreign reputation management should attract more favorable support.

\section{Brand strategy}

There appears to be a tendency to treat reputation and brand identically. However, brand management could be considered as one of the critical factors that compose reputation management. Following the merger in 2004, the importance of having a solid corporate brand was realized, and brand strategy has become a part of the current 3-year strategy, which ends in fiscal year 2008. Corporate brand is defined as "what differentiates ourselves from other market players with outstanding presence and reliability, and functions competitively". The starting point is the value generated by each individual associate, which can be translated as "human power." By implementing unique CSR activity, the company aims to achieve "the highest quality that is accepted, respected, and chosen by customers", and thereby creating corporate brand value.

\section{Quantitative analysis of reputation}

Since reputation is a qualitative concept, it is challenging for a corporate manager to evaluate and disseminate a strategy to manage corporate reputation. There are ongoing studies and trials in the U.S. and European countries on quantification of reputation. For example, Jason Perry and Patrick de Fontnouvelle from the Federal Reserve Bank of Boston released a study on the impact of reputation to the corporate value caused by operational loss events. ${ }^{12}$ According to the study, when the loss was announced, the market value of the company fell almost one-for-one with actual loss amount if it was caused by external events. But when internal fraud was involved in the cause, the market value fell by over twice of the actual loss. The decline of the firm's market value exceeding the announced loss amount is interpreted as a reputational impact, the paper says. Hence, the Corporate Communications Department was instructed to design a method of quantified analysis. The concept is based on the assumption that the contents broadcast through mass media represent reputation among various stakeholders, in which reputation is visualized and analysed thereafter.

sufficient to absorb the emissions associated with the business activities of Tokio Marine \& Nichido. Our aim is to balance the volume of carbon dioxide emissions resulting from our business activities with the volume of carbon dioxide absorbed by reforested mangroves, so as to become "carbon neutral". The project also proved to have great significance in terms of disaster prevention, following the Indian Ocean Tsunami of December 2004, in which a portion of mangroves acted as a wave break.

12 Perry and de Fontnouvelle (2005, pp. 4-5). 
Meanwhile, The Tokio Marine Research Institute ${ }^{13}$ is conducting a research study on quantifying reputation by analysing negative feedback when such keywords as "unforgivable" or "skeptical" appear on internet blogs soon after the broadcast of an insurance company's inappropriate business conduct. In whatever purpose of management, qualitative analysis yields only conceptual measures, and the outcome tends to be short on effectiveness. Introducing a quantitative measure, which is arguably a pioneer case among Japanese companies, is expected to enable a truly functional model of reputation management. The study is in its early stage of development; however, combined with the PDCA (plan, do, check and action) cycle procedure, the introduction of a formalized reputation management system is eagerly awaited. How to reconcile the outcome of the new reputation management system with the results generated by the current corporate valuation system, maintain consistency between these two systems, and refine the credibility of the quantification measures, are further challenges that need to be worked out.

\section{Future goals on reputation management}

\section{Reputation management by multi-stakeholders}

The concept of corporate reputation varies among all stakeholders. Essentially, corporate reputation should be recognized by the total evaluation of stakeholders. In our case, we view stakeholders in the following three ways: (1) multi-stakeholders exist such as customer, agent, shareholder, district or society, associate; (2) each stakeholder can be subdivided into distinctive regional categories such as "Japanese domestic" and "overseas"; and (3) stakeholders can be categorized into "existing" and "future (including prospective)". Although it is a challenging task to manage reputation by each segment as identified above, it is calling for an in-depth study in the future.

In the meantime, attention must be drawn to the aforementioned reputation management methodology based on a quantified model, but further enhancements will follow in order to develop an upgraded methodology, which is capable of highlighting the type and magnitude of actual reputational risk exposure.

\section{How to heighten internal awareness (understanding of CSR practice through core insurance business)}

As previously stated, the origin of reputation conceivably lies with the associates. Therefore, it is important to structure a clear identity within the organization, spread it through internal communication, and then let the message flow through each associate to the outside world. In the case of Tokio Marine \& Nichido, which has established a clear corporate identity to exercise CSR through its core insurance business, it is absolutely necessary to spread the concept to associates worldwide. To communicate, in this context, is to assist all associates in their taking action based on the corporate identity, and support them in understanding the value of the concept so that they will

\footnotetext{
13 Established in April 1992.
} 
actively express it to any stakeholder with whom they interact. It is crucial to reach this level of awareness and share this sense of value to perform truly meaningful reputation management.

Preferably, communicating with each individual associate and sharing the corporate manager's own belief in person would be ideal, but it is clearly not feasible. The realistic approach seems to depend on how to organize corporate structure to help spread the corporate philosophy and strategy in the governance and make it functional.

\section{General goal}

In general, there is no simple remedy to improve corporate reputation. Reputation needs to be addressed with a long-term vision and requires persistency of revisiting past commitments before achieving a solid ground. There is no argument that "truthfulness" and "transparency" have recently been recognized as two of the most important components in discussing corporate reputation. While inheriting the two concepts as the foundation of reputation management, "consistency" and "originality" also need to be pursued.

Considering the implication of reputation management, "reputation" can be seen as a precious management resource, and "management" should not be taken as a mere administrative term, but as a positive concept that represents creative efforts. The author firmly believes that by exercising consistent efforts to provide value to society, which is the corporate identity, and by making the most of the company's originality, the corporate reputation should be enhanced.

\section{Reference}

Perry, J. and de Fontnouvelle, P. (2005) Measuring Reputational Risk: The Market Reaction to Operational Loss Announcements, Federal Reserve Bank of Boston (October 2005).

\section{About the author}

Kunio Ishihara was appointed president of Tokio Marine \& Fire Insurance Company, which has now become Tokio Marine \& Nichido Fire Insurance Company, in June 2001. With the incorporation of Millea Holdings, Inc. in April 2002, he became the first president of the holding company, which owns and operates life and non-life insurance entities worldwide. The author graduated from Tokyo University in 1966, and joined Tokio Marine the same year. 